\title{
NEW ELECTRORETINOGRAPHIC FINDINGS OBTAINED IN CONGENITAL FORMS OF DYSCHROMATOPSIA*
}

BY

\author{
J. FRANÇOIS, G. VERRIEST, AND A. DE ROUCK \\ From the Ophthalmological Clinic of the University of Ghent
}

InVESTIGATIONS made by Motokawa and Mita (1942), Adrian (1945), Gastaut (1949), Johnson (1949), Schubert and Bornschein (1952), Armington (1952), Armington, Johnson, and Riggs (1952), Bornschein (1953), Burian (1954), and Auerbach and Burian (1955), and by other investigators, have revealed that-under suitable conditions of examination-the human electroretinogram (ERG) normally consists of a photopic wave $a_{1}$, a scotopic wave $a_{2}$, a photopic wave $b_{1}$ (or $x$ ), and a scotopic wave $b_{2}$. Investigations made by Wirth (1951), Dodt (1951), Dodt and Wadensten (1954), Heck and Rendahl (1957), Heck (1957), and Rendahl (1958) have shown, among other things, that the $b_{1}$-wave as such is a complex wave, and that the normal human electroretinogram also comprises other visible components, such as the $c$-wave, and several off-effects.

Absence of the $b_{1}$-wave in cases of complete achromatopsia has been described by Vukovich (1952), Yonemura and Ishizaka (1952), Dodt (1954), Wadensten (1954, 1956), Goodman and Iser (1956), Iser and Goodman (1956), Bornschein, Goodman, and Gunkel (1957), Heck and Rendahl (1957), Elenius and Heck $(1957,1958)$ and Schappert-Kimmijser (1958).

Armington (1952) and Schubert and Bornschein (1952) have shown that the ERG is virtually normal in deuteranopia and tritanopia, whereas in protanopia it is difficult to demonstrate the $b_{1}$-wave. Heck and Rendahl (1957) and Rendahl (1958) have demonstrated, among other things, that the $b_{1}$-wave shows changes, not only in protanopia but also in deuteranomaly and deuteranopia.

In a previous publication (François, Verriest, and de Rouck, 1956), we have shown that intermittent stimulation with the aid of a neon light source permits a ready dissociation of the components $b_{1}$ and $b_{2}$ in the ERG of normal subjects (Fig. 1, opposite), and makes it possible to demonstrate the apparent absence of the $b_{1}$-wave in protanomaly, protanopia, and typical achromatopsia (rod-monochromatism) (Fig. 2, opposite). 


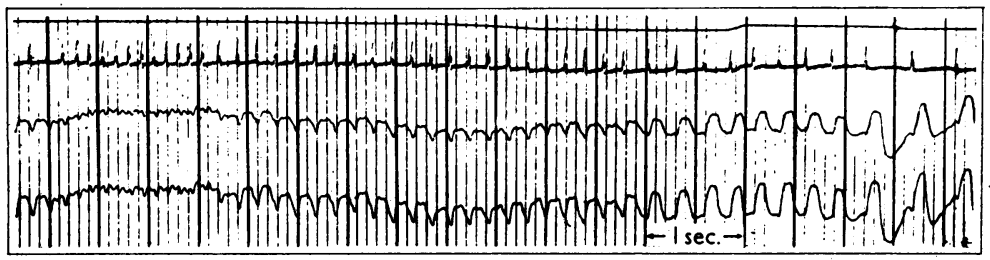

FIG. 1.-ERG after dark adaptation: responses from a normal subject. Neon, various frequencies.
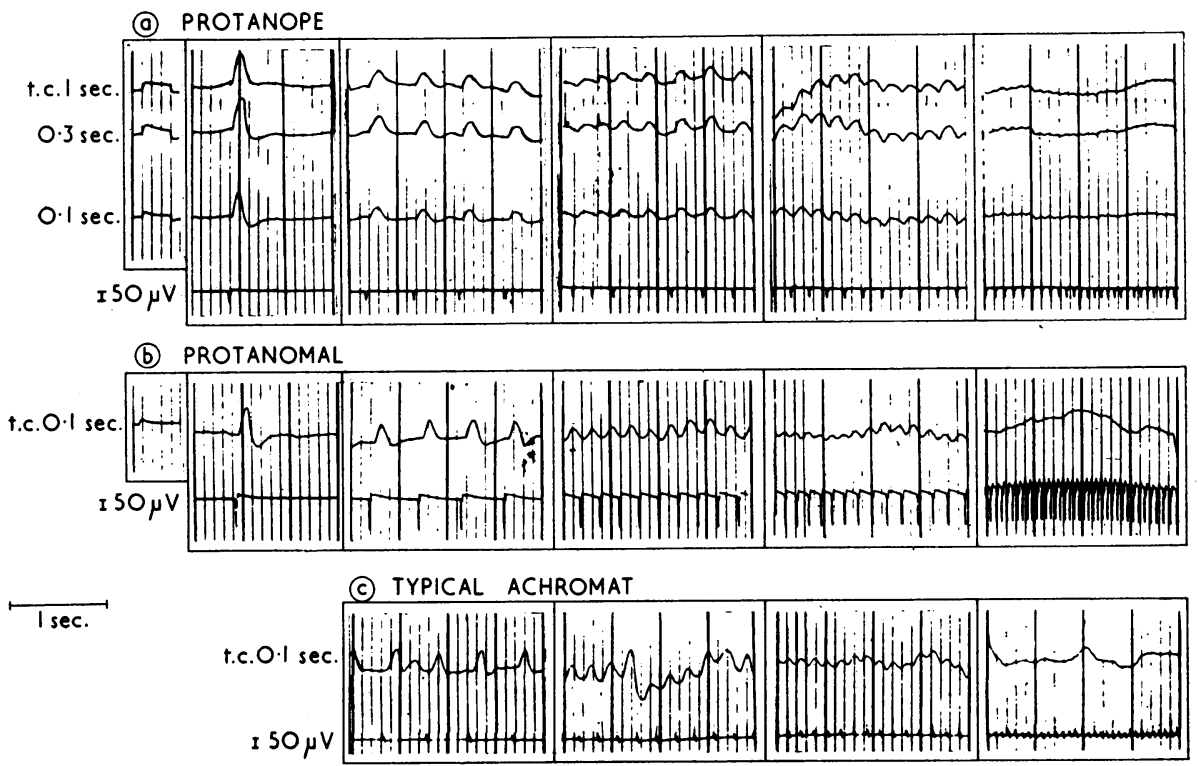

FIG. 2.-ERG after dark adaptation: responses from a protanope, from a protanomal and from a typical achromat. Neon, various frequencies.

\section{Present INVESTigations}

A.-We have so far used this method in investigating ten cases of protanomaly, sixteen of protanopia, eight of deuteranomaly, two of deuteranopia, one of tritanomaly, seven of typical achromatopsia, and one of atypical achromatopsia (François and Verriest, 1959). The eye examined was always dark-adapted before examination. The frequency of the stimulation was four flashes per second, at which frequency the $b_{1}$ - and $b_{2}$-wave are best distinguishable (Fig. 1). 
In cases of deuteranomaly, deuteranopia, and tritanomaly, we obtained perfectly normal ERG findings. In the case of atypical achromatopsia, we found a $b_{1}$-wave of subnormal amplitude.

All cases of protanomaly, protanopia, and typical achromatopsia were characterized by apparent absence of the $b_{1}$-wave (Fig. 2). The amplitude of the $b_{2}$-wave was normal, but its culmination time was longer than that of the $b_{1}$-wave and shorter than that of the $b_{2}$-wave in normal trichromats. The difference was significant, regardless of whether the culmination time was measured from the apex of the $a$-wave ("Culmination Time" in the strict sense of the word) or from the light-flash ("Implicit Time" according to Bornschein, Goodman, and Gunkel, 1957).

Comparing normal subjects with protanopes, we found that the difference $\Delta$ is highly significant (10 S for the Culmination Time and $6 \mathrm{~S}$ for the Implicit Time). The differences were also significant when comparing the single deflection of protanomals, protanopes, and achromats with the $b_{1}$-wave in normal subjects (Table).

TABLE

\begin{tabular}{ll|c|c}
\hline & Subjects & $\begin{array}{c}\text { Culmination Time } \\
(\text { msec. })\end{array}$ & $\begin{array}{c}\text { Implicit Time } \\
(\mathrm{msec})\end{array}$ \\
\hline Normal & $N$ & 7 & 7 \\
& $m$ & $103 \cdot 5$ & $154 \cdot 1$ \\
& $s$ & $6 \cdot 4$ & $6 \cdot 4$ \\
\hline Protanomal & $N$ & 14 & 12 \\
and & $m$ & $69 \cdot 3$ & 121.6 \\
Protanopes & $s$ & $9 \cdot 1$ & $14 \cdot 6$ \\
\hline Typical & $N$ & 3 & \\
Achromats & $m$ & 62 & $28 \cdot 8$ \\
\hline$\Delta=m-m^{\prime}$ & & $34 \cdot 2$ & 4.8 \\
$S=\sqrt{\frac{s^{2}}{N}+\frac{s^{\prime 2}}{N}}$ & & $3 \cdot 4$ & \\
\hline
\end{tabular}

B. - In a second series of experiments, we studied ERG changes during dark adaptation. The entire binocular field of vision was previously submitted to white light adaptation $\left(2,000 \mathrm{asb}, 5 \mathrm{~min} ., 2,750^{\circ} \mathrm{K}\right)$. This was followed by registration, during 15 minutes, of the electrical responses to intermittent stimulation with a neon light source (four flashes per second).

Normal subjects show a $b_{1}$-wave from the onset of registration (Fig. 3, opposite). The culmination time of this $b_{1}$-wave remains constant ( $32 \mathrm{msec}$.), but its amplitude shows a very slight increase. The $b_{2}$-wave appears at the 5 th minute; its culmination time is always above $60 \mathrm{msec}$. and increases until the 15th minute. The same holds true for the amplitude of the $b_{2}$-wave, although this sometimes shows a paradoxical diminution which would seem to be attributable to local adaptation and does not influence the culmination time. 


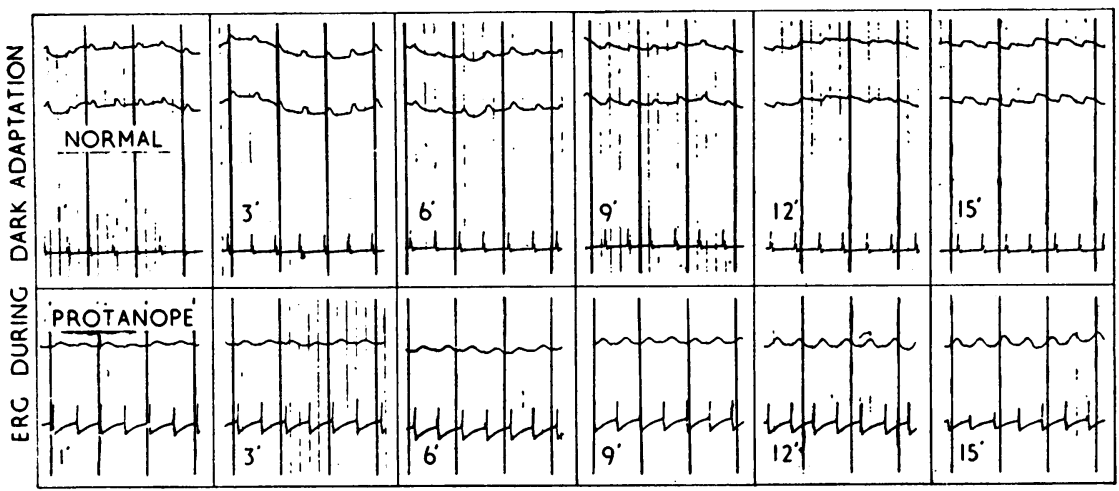

FIG. 3.-ERG during dark adaptation: responses from a normal subject and from a protanope. Neon, 4 flashes per sec.

Deuteranomalous and deuteranopic subjects did not differ from normal subjects. Protanomals, protanopes, and typical achromats, however, showed a single b-wave which was never split into two components (Fig. 3). The amplitude and the culmination time of this wave increased in the course of the experiment like those of the normal $b_{2}$-wave; this single $b$-wave, therefore, would seem to be essentially scotopic (Fig. 4, overleaf).

It should be pointed out, however, that:

(1) The single $b$-wave was visible from the onset of dark adaptation, whereas the normal $b_{2}$-wave does not appear until the 5th minute; from the first minute, the culmination time was $45 \mathrm{msec}$. in protanomaly and protanopia, i.e. considerably longer than the culmination time of the normal $b_{1}$-wave.

(2) The culmination time of the single $b$-wave always remained between that of the $b_{1}$ - and the $b_{2}$-wave in normal subjects.

Statistical analysis showed that the differences were significant. At the 10th minute of dark adaptation, the following culmination times were found:

Normal $b_{1}$-wave

Normal $b_{2}$-wave

Single $b$-wave in protanopes

$$
\begin{array}{lll}
m=32 \mathrm{msec} . & s=1.8 \mathrm{msec} . & N=8 \\
m=95 \mathrm{msec} . & s=18 \mathrm{msec} . & N=8 \\
m=67 \mathrm{msec} . & s=11 \mathrm{msec} . & N=6
\end{array}
$$

The culmination time of the $b$-wave is still shorter in typical achromatopsia (Fig. 4, overleaf). 


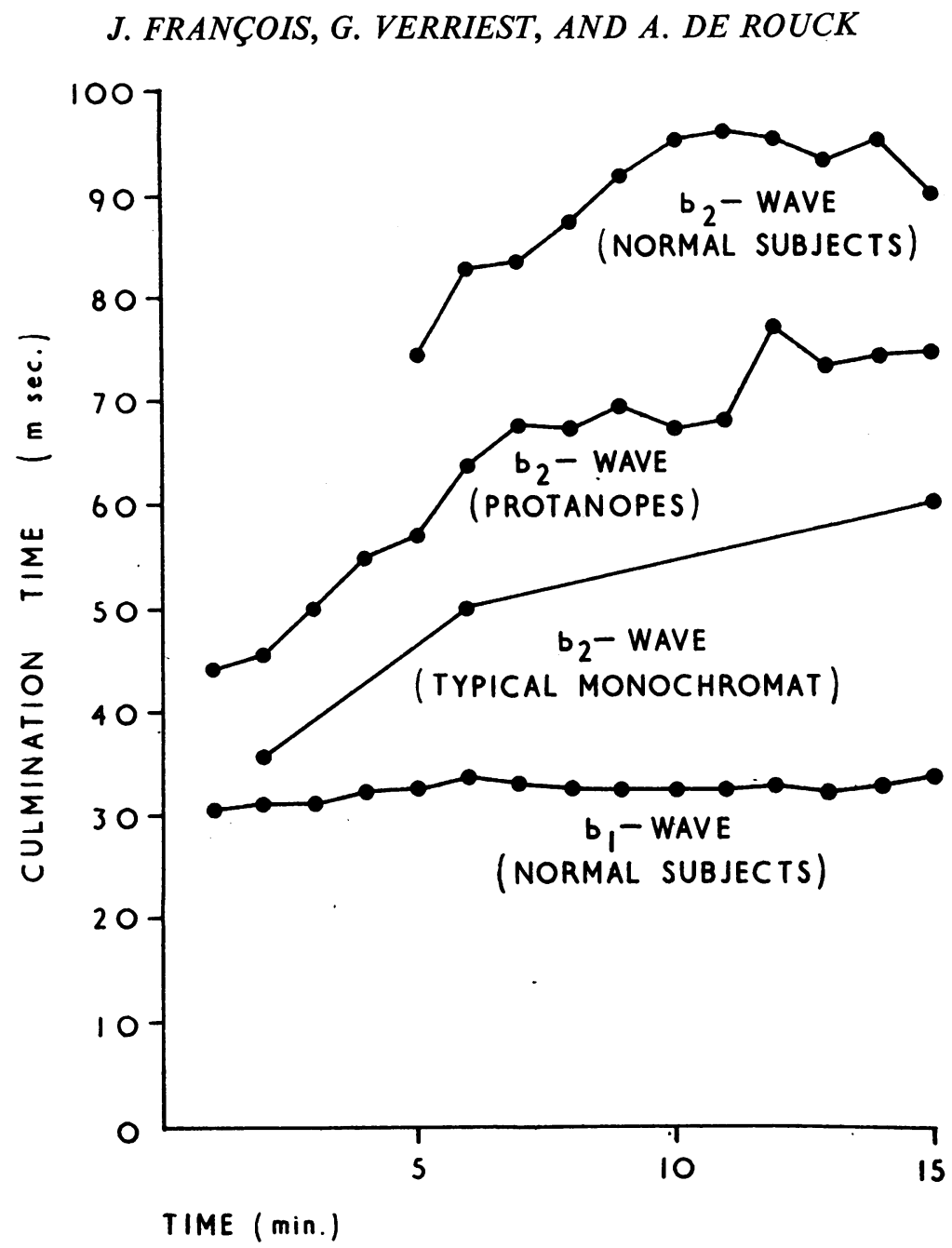

FIG. 4.-ERG during dark adaptation: modification of the culmination times of the $b$-waves from normal subjects (mean values), from protanopes (mean values) and from a typical achromat (singe values). Neon, 4 flashes per sec.

\section{Discussion}

These experiments have not shown that the $b_{1}$-wave is in fact absent in cases of protanomaly and protanopia, since Heck and Rendahl (1957) demonstrated its presence.

On the other hand, it is certain that the culmination time of the only positive deflection seen is decreased in protanomaly, protanopia, and typical achromatopsia, as compared with the culmination time of the normal $b_{2}$-wave.

This decrease in culmination time does not correspond with a change in amplitude as in normal subjects (Bornschein, Goodman, and Gunkel, 1957). 
It must be due either to a collapse between the photopic and scotopic mechanisms, or, more probably, to the diminution or absence of the inhibition normally exerted on the scotopic mechanism ( $b_{2}$-wave) by the photopic mechanisms.

Elenius and Heck (1957) also accepted this hypothesis to explain the differehces between the amplitude curves of the $b$-wave in normal subjects and those in achromats during dark adaptation.

\section{Summary}

It is shown that, by intermittent stimulation with a neon stroboscope during and after dark adaptation, it is normally possible to obtain duplication of the ERG $b$-wave into photopic and scotopic components $\left(b_{1}\right.$ and $\left.b_{2}\right)$.

The results obtained in deuteranomalous, deuteranopic, and tritanomalous subjects were identical to those obtained in normal subjects.

Protanomals, protanopes, and typical achromats, however, alwaysunder similar conditions-showed a single $b$-wave, of which both the culmination time and the implicit time were between that of the two normal components. The differences are statistically highly significant.

The single deflection seen in these subjects may be regarded as a $b_{2}$-wave, the culmination time of which has been reduced by diminution or absence of the inhibitory effect normally exerted by the photopic mechanisms.

One patient with atypical achromatopsia showed a double $b$-wave, but with a diminished amplitude of the $b_{1}$-component.

\section{REFERENCES}

Adrian, E. (1945). J. Physiol. (Lond.), 104, 84.

Armington, J. C. (1952). J. opt. Soc. Amer., 42, 393.

Johnson, E. P., and Riggs, L. A. (1952). J. Physiol. (Lond.), 118, 289.

- JoHnson, E. P., and RIGGs, L. A. (1952), J. Physiol. (Lot

Auerbach, E., and Burian, H. M. (1955). Amer.J. Ophthal., 40, No. 5, Pt 2, p. 42.

BORNSCHEIN, H. (1953). Z. Biol., 105, 454.

Bornscien, Goodman, G., and Gunkel, R. (1957). A.M.A. Arch. Ophthal., 57, 386.

BuRIAN, H. M. (1954). Ibid., 51, 509.

DODT, E. (1951). v. Graefes Arch. Ophthal., 151, 672.

(1954). Experientia (Basel), 10, 330.

- and WADENSTEN, L. (1954). Acta ophthal. (Kbh.), 32, 165.

EleNIUS, V., and HECK, J. (1957). Nature (Lond.), 180, 810.

FrançoIs, J., and VerRIEST, G. (1959). Ann. Oculist. (Paris), 192, 81.

FrançoIs, J., and and DE RoUCK, A. (1956). Brit. J. Ophthal., 40, 439.

Gastaut, H. (1949). Electroenceph. clin. Neurophysiol., 1, 205.

Goodman, G., and Iser, G. (1956). Amer. J. Ophthal., 42, No. 4, Pt 2, p. 212.

HeCK, J. (1957). Acta physiol. scand., 39, 158; 40, 113.

I. and RENDAHL, I. (1957). Ibid., 39, 167.

Iser, G., and GoODMAN, G. (1956). Amer. J. Ophthal., 42, No. 4, Pt 2, p. 227.

JoHnson, E. P. (1949). J. exp. Psychol., 39, 596.

MotokAWA, K., and MrTA, T. (1942). Tohoku J. exp. Med., 42, 114.

RENDAHL, I. (1958). Acta physiol. scand., 44, 189.

SCHAPPERT-KIMMIJSER, J. (1958). Ophthalmologica (Basel), 135, 147.

SCHUBERT, G., and BORNSCHEIN, H. (1952). Ibid., 123, 396.

VuKOVICH, V.'(1952). Ibid., 124, 354.

WADENSTEN, L. (1954). Acta ophthal. (Kbh.), 32, 743.

- (1956). Ibid., 34, 311.

WIRTH, A. (1951). v. Graefes Arch. Ophthal., 151, 662.

YONEMURA, D., and IsHzAKA, N. (1952). Rinsho Ganka, 6, 154. 